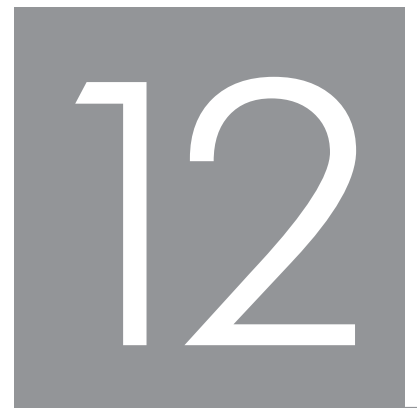

\title{
WORKING WITH NON-PROFIT ORGANISATIONS DURING AN INTERNATIONAL FIELDTRIP
}

\section{REFLECTIONS ON EFFORTS TO IMPROVE RECIPROCAL RELATIONS}

\section{Daniel Hammett \& Daniel Vickers'}

\section{ABSTRACT}

International field class teaching provides an opportune moment to turn experiential learning into a process of knowledge enablement and knowledge transfer. This chapter reflects on the experience of an international field class by development geography students from the United Kingdom who visited South Africa in March 2013. Critical reflections address the ways in which the course was adapted to increase the service learning and knowledge enablement outcomes of the field class, and the benefits and challenges faced by students and host non-profit organisations in this process. Key challenges identified include clarity and quantity of communication among stakeholders in the designing of research projects and concerns over students being a burden to the host non-profit organisation. At the same time, benefits to students' learning outcomes as well as to strengthening non-profit organisations' practices are identified, along with a number of simple measures that could enhance the reciprocal outcomes of such engagements.

1 With contributions from Jennifer Allenby, George Barrett, Andrew MacLachlan and Siân Parkinson 


\section{INTRODUCTION}

The role and contribution of the university sector to society remains in the spotlight - whether in relation to the 'impact' and accessibility of academic research on the general public, the type of citizens shaped by universities, the political and social responsibilities of academics, or driving economic growth. The framings of these agendas and imperatives vary over time and by national context. In the United Kingdom (UK), these debates have been driven by a neo-liberal agenda of 'impact' and reaction against it, which prioritises a more critical and activist role for the academy (Massey 2004; Williams 2012). South African government policies and initiatives provide a grand vision for the role of higher education in developing the post-apartheid nation (Lazarus, Erasmus, Hendricks, Nduna \& Slamat 2008) that resonates with an existing culture of practice in which developmental and social justice concerns are entrenched in South African intellectual identities (Connell 2007; Parnell 2007). Among human geographers, this culture of practice emphasises collaboration with local communities and draws from earlier engagements with anti-apartheid civil society campaigns to inform efforts to contribute to postapartheid nation building and development (Oldfield 2007, 2008; Oldfield, Parnell \& Mabin 2004; Parnell 2007).

Within human geography, field class teaching and research provide an opportune moment in which to critically engage with these concerns and seek to involve staff, students and local organisations or communities in reciprocal relations of co-learning and knowledge co-production (Driver 2004; Herrick 2010; Malam \& Grundy-Warr $2011)$. Building on these concerns, and acknowledging the influence of postcolonial approaches to research practice (Simon, Mosavel \& Van Stade 2007), this chapter reflects on the possibilities for pursuing co-learning and knowledge co-production afforded by an undergraduate development geography fieldtrip from the UK to South Africa during which students from the University of Sheffield worked with nonprofit organisations (NPOs) in Bloemfontein, Free State, South Africa.

The chapter begins with an overview of experiential learning within human geography as a mechanism for developing research and teaching with non-academic partners. We then outline the philosophy behind and logistics of the fieldtrip before reflecting on the successes and challenges experienced in designing and delivering a collaborative learning experience to benefit students and host NPOs.

\section{SERVICE LEARNING, GEOGRAPHY FIELDTRIPS AND 'IMPACT'}

Community engagement has developed as a core concern in university research and teaching, often embedded in service learning activities (Lazarus et al 2008; 
Reed, Jernstedt, Hawley, Reber \& DuBois 2005). Service learning can be defined as participation in an activity that meets community needs and involves student reflections upon such an activity. Advocates of service learning argue that this approach provides students with skills development, enhanced understanding and a platform through which to link theory to experience, while potentially transforming students' worldviews and daily practices through engagement with social problems (Braunsberger \& Flamm 2011; Lazarus et al 2008). In addition to improving the students' educational experience, service learning is recognised as fostering and developing a democratic community, increasing civic engagement and providing a basis for education for social transformation (Braunsberger \& Flamm 2011 ; Saltmarsh 1996). While service learning contributes to the development of students as informed and engaged citizens, it also promotes community engagement and draws students into the role of knowledge transfer facilitators and participants in reciprocal learning experiences (Oldfield 2008; Thomson, Smith-Tolken, Naidoo \& Bringle 2011 ).

Community engagements within service learning approaches are based upon ideals of equality and participation, including that educational objectives and community partner needs are aligned through a process of mutual negotiation "to enhance, among other objectives, reciprocal learning" (Thomson et al $2011: 214$ ). The benefits of reciprocal learning - of sharing knowledge, ideas and skills - can assist NPOs in strengthening their capacity and realising specific targets and goals, while also contributing to broader social development, poverty alleviation and transformative agendas (Parnell 2007; Stanton \& Erasmus 2013). To realise these outcomes, strategies of consultation and negotiation are needed to ensure that partner organisations are valued and respected and are not placed in a position of being in service to a university course and student needs (Oldfield 2008). These practices, which resonate with postcolonial approaches to development research, serve to address the power inequalities often implicit in the designing and conducting of research - processes that are led by academics or students with little cognisance of the needs or priorities of host organisations or communities. Instead, service learning approaches seek to involve host communities or organisations in consultations around the formulation of research ideas and design of research projects to ensure robust and sensitive research that is relevant, useful and accessible to different stakeholders (Simon et al 2007).

These engagements contribute to an ongoing process of reflexivity and critical thinking throughout the research process and a heightened awareness of the influence of the positionality of the researchers over their research practice and findings. This recognition of the influence of previous emotional, ideological and 
intellectual experiences on our engagement with the field, allied to awareness that our presence as researchers influences the context and practice of knowledge production, allows us to recognise that knowledge is co-produced through a process involving both the researcher and participants (Kaufmann 2002). Understanding the mutuality of knowledge co-production further underscores the need for a strong ethic of reciprocity within research practice and efforts to deliver on the ideals of fieldtrip teaching in a way that benefits both students and host communities/organisations.

Although human geography fieldtrips cannot be equated with service learning pedagogy, many such trips do draw upon similar ideals and practices. Fieldtrips and fieldwork are viewed as crucial components of a geography degree that offers experiential learning opportunities to students that prompt deeper learning, critical thinking skills and a chance to question the politics and merits of knowledge production and acquisition (Fuller 2012; Hill \& Woodland 2002). However, the practices and outcomes of fieldtrips vary dramatically depending upon the disciplinary and pedagogical underpinnings, geographical location and subjective focus, and the duration and style of participation involved.

The University of Sheffield's fieldtrip to Bloemfontein discussed here cannot be positioned as a 'true' service learning project, but it can be considered as a short-term engagement infused with postcolonial principles and the ethos of service learning. To this end efforts were made to ensure that both students and host NPOs were involved in the design of the research projects, that the focus of the research would be of benefit to the individual NPOs and that students' findings would be provided to their hosts in appropriate ways in order to ensure a reciprocal relationship between the student and host NPO. Furthermore, underpinning the pedagogical approach to the fieldtrip and specified learning outcomes are concerns to provide students with an experience that links education (and theory) to experience and everyday life and that such experiences encourage and foster democratic practice and deeper social engagement and transformation - all of which resonate with Saltmarsh's (1996) key outcomes of service learning. Overall, the fieldtrip resonates with a form of shortterm service learning and can be recognised as providing (albeit in a limited way) a means of promoting a sense of social responsibility and increasing a sense of the meaningfulness of university education (Reed et al 2005).

\section{THE FIELDTRIP}

The reflections in this chapter are based on an 11 day development geography fieldtrip to South Africa in March 2013 involving 30 final year honours level 
students accompanied by three staff members from the University of Sheffield. All three staff members had visited South Africa before, but only the course leader had conducted research in the country and visited Bloemfontein previously. The students were generally from middle-class backgrounds with a mixture of previous travel experience; some had travelled extensively and independently to domestic and international destinations; for others the fieldtrip was the furthest they had travelled and for some it was the first time they had travelled overseas.

The fieldtrip involved a range of teaching and learning activities in Johannesburg, Pilanesberg and Bloemfontein, including experiential learning activities that could be characterised as involving autonomous observation (self-guided tours of the Apartheid Museum), dependent observation (a staff guided 'Cook's tour' of Bloemfontein), and autonomous participation (student-defined interactive data gathering during research with the host NPO) (Herrick 2010; Panelli \& Welch 2005). Bloemfontein was the primary fieldtrip location. Here, students were provided with a day of orientation activities before spending three days working in small groups (five students per group) with one of six local host NPOs to conduct a small-scale research project. The findings and experiences of this research formed the basis for an individual research report, a group policy brief and mapping product (to be shared with the host NPO) and a reflective essay on development research practice.

The host NPOs were identified as potential partners during a pre-fieldtrip planning visit in August 2012 when the fieldtrip leader made contact with the Head of Service Learning (HoSL) at the University of the Free State. Through a series of meetings and site visits a shortlist of potential host NPOs was identified and invited to host a small group of University of Sheffield students. Conversations with the host NPOs addressed concerns relating to the design of the students' research projects, their activities during the visit, as well as the provision of findings and products to the host organisations. From these conversations, and discussions with the HoSL, it became clear that the NPOs would value a mapping product that would either assist in their daily practices and/or provide a material resource that could be used in efforts to secure funding and support for their work. This request was driven, in part, by an expectation that students would be proficient in and have access to basic Geographic Information System (GIS) tools, as well as by dominant views of geographical studies outside of academia.

This request was discussed by the fieldtrip teaching team to identify how to integrate the relevant output in the students' work. It was decided to embed the mapping exercise within the assessment materials for the module, specifically as a required component of the group policy brief output. The decision to include the mapping 
product in the module's assessment reflected our concerns that although the fieldtrip participants were an engaged group of final year students, there was a significant risk: If the mapping exercise were positioned as an activity which did not bear credits, it would either not be completed or it would be completed at a minimum level. Once the decision to include the mapping project was reached we also amended aspects of the pre-fieldtrip teaching to ensure that students received training in various mapping techniques and appropriate technology. Therefore, in order to embed the NPOs' request in the module, alterations were made to the module assessment and teaching content.

Prior to the fieldtrip, the students had all undertaken at least one module on development geography and had attended a series of lectures for the fieldtrip module providing an introduction to the socio-political context of the fieldtrip, as well as training on research methods. Students had also been instructed to correspond with their host NPO prior to the fieldtrip in order to develop their research projects in collaboration with their hosts. During the research each student group was accompanied for some time by a member of the academic staff, but the students retained leadership of their research projects and practice. Upon completion of the fieldtrip, students were required to submit a short research report, a reflective essay on a component of their fieldtrip experience, a policy brief and mapping product. Students shared the policy brief and mapping product with their host organisation, and a number also provided copies of their research reports to the NPOs.

The reflections presented in this chapter are drawn from two of the academic staff, four students and three NPOs. All 30 students were invited to collaborate in producing this chapter, with seven initially agreeing to participate. However, only four students eventually provided reflections and inputs. All six host NPOs were approached for feedback on their experience of the fieldtrip, with four providing comments.

\section{INTEGRATING PARTNERS INTO THE RESEARCH PROCESS AND ACHIEVING RECIPROCITY}

As noted, the design and conduct of the fieldtrip was intended to ensure the participation of host NPOs throughout the research process and that the students' research findings would be shared with the host NPOs. In reflecting upon these experiences, we discuss various challenges, positive outcomes and memorable experiences, and ways in which the fieldtrip improved learning outcomes and sought to use the knowledge developed during the research as a beneficial, enabling product for the host NPOs. 


\subsection{Negotiating access and collective understanding}

The philosophy of service learning and postcolonial research approaches emphasise the importance of engaging host organisations throughout the project's lifespan in order to identify research needs and appropriate research activities that will benefit both host organisations and service learning students (Oldfield 2008). The initial contact and discussions among the course leader, a local gatekeeper (HoSL) and the host NPOs were essential to establish links, access and common understanding. However, one of the biggest challenges to the fieldtrip (and to the generation of research outputs of benefit to host NPOs) related to clarity of communication and understanding of the purpose and scope of the fieldtrip. Although this is an issue for all researchers, it is heightened in relation to student engagement: Whereas experienced researchers may anticipate and pre-empt challenges arising from a lack of communication or a rapidly changing research context and think ahead to provide briefing notes or other outputs to host organisations as a professional courtesy, this professional practice is not integral to student experience and expectations.

In part, these difficulties arose from the fact that this was the first time, both in terms of geographical location and structure (ie working with host NPOs), that this fieldtrip had occurred. As a consequence, the entire process of preparing and running the fieldtrip was a learning experience for all involved, resulting in a lack of specificity and detail to certain requests or information provided by the course convenor to both host NPOs and students. Compounding this situation was wide variation in both the quantity and detail of communication between student groups and their host organisation prior to our arrival in Bloemfontein. As a result, some groups struggled to identify suitable projects to carry out, while other students struggled to place their research in the context of the field trip location. At the same time, despite a wealth of existing literature covering the issues likely to be encountered during the fieldtrip, many students found these links much more difficult to make than academic researchers and often focused solely on the specifics of the research site from the outset, rather than engaging research from similar contexts and applying this to their research design. The following are excerpts from the students' responses:

A major challenge of the whole research experience was having to define an area of research interest with minimal contact with the host organisation before arrival. We were not able to identify major challenges to the [NPO] until initial conversations with NPO management (Andrew).

Another challenge was the miscommunications with the charity of what our research entailed. As they didn't quite understand that we were conducting research they provided little opportunity to gain any relevant interview data from them (Jennifer). 
Due to limited contact from the host organisation prior to the research experience, the research topics had to be broad to allow for flexibility. Although our group had a rough plan of the questions and topics we wished to cover, we could not formulate a specific plan of action as we weren't able to fully assess the research environment until we spoke with the host organisation and had a clearer idea of the participants (Siân).

Thus, while the course leader and students attempted to ensure that the NPOs were actively engaged throughout the research process and that the work done by the students was relevant to and useful for the host NPOs, this process was only partially successful and at times frustrating (Simon et al 2007).

For a number of students, the uncertainties regarding the specific focus of their work were exacerbated by their lack of previous experience of research in the field, contributing to feelings of nervousness and insecurity. While preparatory work and reading is essential to provide a foundation for the fieldtrip, this does not fully convey the intricacies and visceral nature of field experience. As two of the students noted:

The biggest challenge that I noted from the research experience was that no matter how much research you do about the topic in question that you're going to study in the field, it will not prepare you for what you are actually going to see and do out there (Jennifer).

After spending weeks naïvely assuring ourselves that we had planned for every possible eventuality we were likely to experience during our research project it was not until we actually met our host organisation that we became aware of some of the challenges we were likely to face (George).

While these experiences may have been discomforting and challenging, they contributed to accelerated learning and greater understanding of the realities of conducting development research, an experience that cannot be provided in the classroom. In working through these challenges, the students developed a range of research and other transferable skills while increasing their understanding not only of the local context and challenges, but also of the complexities of conducting development fieldwork (Braunsberger \& Flamm 2011 ; Lazarus et al 2008).

The importance of negotiating access, research focus and research products of mutual benefit was a core feature of this fieldtrip - even if there were multiple challenges to these engagements. Not only did such engagements begin to recognise and mitigate continued power relations within development but they also - albeit partially - allowed participants a degree of control and power over the co-production of knowledge. To improve on these experiences, increased clarity and frequency of communication and expectations would be vital - for both NPOs and students (not least in managing their expectations and reminding them of the difference between 
doing 'development' and doing 'development research') to ensure research findings and products are relevant and useful. In so doing, this would also help to maintain rapport and trust between external fieldtrips, local facilitators and host NPOs. This is further exacerbated by the generally naïve nature of student expectations, assuming straightforward and organised research settings within the framework of development research.

\subsection{Time, logistics and 'being a burden'}

Compounding the challenges noted above regarding pre-fieldtrip communication were a number of logistical factors that served to limit the possibilities for more engaged and long-term service learning practices. Time played a key role in this set of circumstances. The overall length of the fieldtrip ( 11 days) was largely dictated by precedence, timetabling limits and cost, while logistical factors and pedagogical outcomes of the fieldtrip as a whole determined the curtailed time spent working with host NPOs (3 days). The time factor is a complex issue, one with competing priorities and concerns. A number of students and host NPOs identified the need for more time to allow for useful findings to be produced:

I think 3 days was too short a time for them to get done what needed to be done, this also being the reason why things felt a little rushed (NPO 1).

A significant challenge of the research experience was the restriction of time. Only having a few days to speak with participants meant that, though our research needed to be flexible, it also needed to be well-planned to ensure we made the most of the time available to us. The time limit also meant that there was difficulty meeting with some desired participants due to their own availability and so we were required to prioritise our time. All of these challenges emphasised the importance of flexibility and ability to adapt to differing circumstances depending on the research experience (Siân).

At the same time, there was concern among the course teaching team and some students and NPOs about the burden placed upon the host organisations by the presence of the student groups. While the host NPOs commented on the benefits of hosting the student groups and of interacting and deepening understanding through participation in the projects, a degree of disquiet remained at times that staff and resources were diverted to hosting the student groups and away from the daily activities of the NPO. This dilemma was distilled by one of the students whose reflections on these complexities demonstrate this tension:

One of the major issues we were faced with was that we were very wary as a group of visitors that we didn't want to be a detriment to the day-to-day running of the NGO, which thus impinged on the limited time we had to collect data

... This potentially could have been alleviated had we initially had greater 


\section{CHAPTER 12 - HAMMETT \& VICKERS}

communication with the host organisation and been able to provide them with more information of our aims and plans and for us to gain a better understanding of the day-to-day running of the NGO (George).

This concern is pervasive in much development research and underlines the importance of ensuring adequate and clear communication in the developing of such fieldtrips. Deeper understanding of the skills offered by the student groups and a clearer sense of what research would be both feasible and beneficial for the host NPO would help mitigate concerns about the burden placed on NPOs in hosting student researchers (Oldfield 2008). While all the NPOs were incredibly welcoming and hospitable to the student groups, there were times when some NPOs placed an unnecessary burden on themselves by ensuring that their staff or volunteers were always accompanying the students.

\subsection{Enhancing (learning) outcomes}

The decision to base the fieldtrip around a short, intense period of research with a host NPO was designed to enhance student learning - through the development of research skills and engagement with broader ethical and conceptual questions, both substantive and methodological - while seeking to ensure that the host NPOs also benefited from their participation. In this way, it was hoped that both student learning and NPO practice would be enhanced, while also avoiding the danger of a one-way process of 'data mining' or 'data extraction'.

The students' responses clearly indicate that their research and communication skills developed through the intensive fieldwork period:

The research experience built on a great number of research skills that are not often required when working on assignments using secondary evidence (Siân).

Having the freedom to employ a diverse array of research methods was another positive. After utilising more formal and conventional research methods throughout our course, having the liberty to collect data using more unorthodox methods, such as walking interviews, was a new and valuable experience. The informality of the walking interviews often led to far richer data being collected and often enabled the hosts to provide greater context (George).

As well as developing these skills, a process identified as a key benefit of experiential learning (Lazarus et al 2008), a number of students also commented on their realisation that their presence and interaction with NPO staff and clients opened up new conversations and avenues of communication and, in so doing, could provide another means for marginalised groups to be heard: 
Being able to work as an informal platform where users could express their concerns with how the NGO was run meant the research provided an opportunity for some residents to speak openly about their experiences. Whilst this was very emotional for some, they insisted they must finish their story, and in the following days thanked us and told us they felt much better about life for being able to share their history (Andrew).

This realisation of the potential power and role of research was notable for several students, and fitted to a broader growth in self-reflection and development of critical thinking and awareness of civic and social citizenship and responsibility. This awareness was expressed most succinctly in George's observation:

The brief moments I spent in the house of a family whose daughter had had to drop out of school to support her parents who were both suffering from HIV/Aids is something that will stay with me. It was only then I realised how far-reaching the implications of the disease are. You are always simplistically taught in GCSE and A-Level classes ${ }^{2}$ that education will solve poverty; however, I quickly realised that this young girl's education and life chances had been entirely surrendered so she could emotionally and financially support her ailing parents alongside her younger siblings (George).

It was surprising, however, that there was little in the way of critical reflection among the student group on the juxtaposition of the relative luxury enjoyed by the fieldtrip (in terms of the hotel, transport and food) and their encounters with poverty and deprivation during their work with the NPOs. Although the students mentioned this anomaly a few times, the matter was rapidly subsumed by the next social activity and was not subjected to sustained reflection. Such a tension is not confined to fieldtrips of this nature, but is a common feature of development research (and practice), and is an area that would benefit from greater explicit consideration in future fieldtrips.

For the host NPOs, a number of positive outcomes were mentioned as emanating from their hosting of the fieldtrip groups. Most prominent among these was a reflection that while hosting the students had placed a burden upon their organisations' time and resources, this had served to energise and enrich their staff:

Hosting the students took some energy from us. But, that [exposing people to our work] is one of our prime focuses. It's also very energising to think on the interesting questions students ask and try to come up with adequate answers (NPO 2).

2 GCSE is the acronym for General Certificate in Secondary Education, the examinations taken by all school students in the UK at the end of year 11 of schooling (usually at 16 years old). A-Levels are Advanced Level qualifications, gained at the end of year 13 of schooling (usually at 18 years old). For the students involved in this fieldtrip, GCSEs would have been the final compulsory year of schooling, with A-Level studies optional further study (prior to university). 
It was a pleasure to have the students with us. The group assigned to us were a group of lovely young people who did their best during their time with us. They were really very considerate of our busy schedule and did their best to not be a disturbance for us. Overall a positive experience for all of us here (NPO 1).

Having the students with us was no burden: It is something you have to set time apart for and enriched your life and work experience (NPO 3).

The research that the students did about our organisation provided us with updated information on our environment that we do not always have time to get hold of for ourselves (NPO 4).

The roles played by the students, as researchers and intermediaries, not only meant that their findings through the research projects could help strengthen the work of the host NPOs (Stanton \& Erasmus 2013), but also positioned students as knowledge transfer facilitators and participants in processes of reciprocal learning (Oldfield 2008; Thomson et al 2011).

In addition to these experiences during the fieldtrip, the NPOs received copies of research findings (policy briefs and mapping products) from the students. While previous development geography fieldtrips to Kenya had utilised policy briefs as a means of providing findings to local officials, the mapping product was introduced for this fieldtrip at the request of the local facilitator as something that would be useful for the daily endeavours of the NPOs. Although it was not a major undertaking, meeting this request did require rearrangement of the student assessment. While these products presented a challenge in identifying what to map (that would be beneficial to the NPOs), the creativity they demanded and conversations they prompted ensured that they were beneficial to both students and NPOs. The negotiation of the type and content of products served to ensure that they were relevant to the host NPO, and in some cases have been used as resources for professional development by the organisations. Assessment had to be the same for all students, but the mapping project lent itself more clearly to the work of some of the group projects than others. Although more than one of the NPOs suggested that clear communication was something they would benefit from, there was little or poor clarity of communication between the NPOs and student groups as to what they wanted. There was further tension in students' narrow understanding of the term 'mapping' and how this linked to the assessment. The concession in including this within the students' work was a source of negotiation between staff and some of the student groups while undertaking the research:

The host organisation told us of a conference they had planned and so we sent our research findings back to them before that date. Additionally we gave 
feedback to the host organisation during our time with them to ensure they were aware of our progress whilst we were with them (Siân).

The research generated individual projects and a group policy brief. The group policy brief was used to identity what the NGO does, what restrictions are encountered, and what can be improved upon. They were very keen to receive the document to use as literature for potential future sponsors. The management also expressed interest into what users felt could be improved upon, and how we as researchers could identify issues that they were perhaps oblivious to (Andrew).

Our initial research topic was unsuitable for the charity. Therefore a new research topic had to be thought of which did not only benefit us as researchers. As part of our research project a map was created of the area that the charity worked in. Initially we thought it would be beneficial if we mapped the services in the area for the charity. However, upon completing a walking tour of the area it became apparent that they already knew where all the relevant services were. Again a rethink was needed. After several interviews and discussions with the charity volunteers and workers it was noticeable that one of the issues facing them was not knowing the distance which the children travelled to see them. A map was therefore created showing them the distances the children travelled and areas of concern and danger across the route in the hope that this may aid them in devising a walking bus scheme in order to help protect the safety of the children (Jennifer).

Overall it is apparent that the service learning inspired approach to this fieldtrip served to enhance the learning experience of the students while also providing beneficial outcomes and materials to the host NPOs. Central to realising these positive outcomes was the process of discussion and negotiation with the host NPOs as to areas of research and types of materials produced that would benefit them, as well as meeting the assessment needs of the students.

\section{CONCLUSIONS}

The experiences from this development geography fieldtrip indicate the continued importance and benefits of experiential learning for students. They also highlight the importance of careful pre-trip planning and preparation, and the key role of trust. The willingness of the host NPOs to welcome the University of Sheffield students was based upon their trust in and previous engagement with the service learning programme at the University of the Free State, which supported the Sheffield fieldtrip only after trust had been developed between the fieldtrip leader and the Head of Service Learning. Integral to gaining this support was a commitment from the fieldtrip leader to ensure that the host organisations were involved in the planning and design of the research projects and that outputs from the research would be designed for and provided to the host NPOs. 
The positive reflections expressed by various stakeholders involved with the fieldtrip resonate with the broader literature advocating the benefits of service learning. For students, the service learning style of the fieldtrip benefitted their ability to link theory to experience; engage classroom learning with real-world encounters, thus prompting greater self-reflection; and develop a stronger recognition of the complex and multifaceted aspects to social problems and developmental challenges (Reed et al 2005). At the same time it is clear that there were weaknesses to this fieldtrip. If these weaknesses were to be rectified, the reciprocally beneficial outcomes of such engagements would be enhanced. Firstly, a change in emphasis and timetabling for the fieldtrip would be beneficial, thus allowing students and NPOs to work together for a slightly longer period in order to develop deeper understanding and more detailed research findings. Secondly, greater clarity and scope of communication between students and NPOs would have been mutually beneficial in ensuring that expectations were accurate, and that time and resources could be most effectively utilised. Thirdly, additional mechanisms to facilitate further communication and sharing of findings, including time for the student groups to provide preliminary findings to the host NPOs through an interactive forum during the fieldtrip, could further strengthen reciprocal learning outcomes.

Overall the collaborations built prior to and during the fieldtrip were a positive experience of knowledge enablement for the parties involved and have provided the foundations for further collaborative engagements. In the months since the fieldtrip, the course leader has been in negotiation with a number of the host NPOs to arrange long-term research placements for postgraduate students from the University of Sheffield to spend six to eight weeks with an NPO as part of their international development degree course. Again, the negotiations begin with a conversation around the willingness of an NPO to host students and for the NPO to lead the identification of topics or areas of research that would most benefit the organisation. Once the students are paired with the host NPO, both parties engage in an ongoing dialogue to design and implement a research project, the findings of which are both useful to the host NPO and assessed for the students' degree course. These developments show how a commitment to postcolonial values in development research and to service learning ideals can contribute to the evolution of ongoing, deeper and mutually beneficial relations over time.

\section{REFERENCES}

Braunsberger K \& Flamm R. 2011. A mission of civic engagement: Undergraduate students working with nonprofit organizations and public sector agencies to enhance social wellbeing. Voluntas, 24:1-31. 
Connell R. 2007. The heart of the problem: South African intellectual workers, globalization and social change. Sociology, $41(1): 11-28$.

Driver F. 2004. Field-work in geography. Transactions of the Institute of British Geographers, 25(3):267-268.

Fuller I. 2012. Taking students outdoors to learn in high places. Area, 44(1):7-13.

Herrick C. 2010. Lost in the field: Ensuring student learning in the 'threatened' geography fieldtrip. Area, 41 (1):108-116.

Hill J \& Woodland W. 2002. An evaluation of foreign fieldwork in promoting deep learning: A preliminary investigation. Assessment and Evaluation in Higher Education, 27(6):539-555.

Kaufmann J. 2002. The informant as resolute overseer. History in Africa, 29:231-255.

Lazarus J, Erasmus M, Hendricks D, Nduna J \& Slamat J. 2008. Embedding community engagement in South African higher education. Education, Citizenship and Social Justice, $3(1): 57-83$

Malam L \& Grundy-Warr C. 2011 . Liberating learning: Thinking beyond 'the grade' in fieldbased approaches to teaching. New Zealand Geographer, 67:213-221.

Massey D. 2004. Practising political relevance. Transactions of the Institute of British Geographers, 25(2):131-133.

Oldfield S. 2007. Making sense of multiple conversations: Research, teaching and activism in and with communities in South African cities. South African Geographical Journal, 89(2): 104-110.

Oldfield S 2008. Who's serving whom? Partners, process, and products in service-learning. Journal of Geography in Higher Education, 32(2):269-285.

Oldfield S, Parnell S \& Mabin A. 2004. Engagement and reconstruction in critical research: Negotiating urban practice, policy and theory in South Africa. Social and Cultural Geography, 5(2):285-299.

Panelli R \& Welch R 2005. Teaching research through field studies: A cumulative opportunity for teaching methodology to human geography undergraduates. Journal of Geography in Higher Education, 29:255-577.

Parnell S. 2007. The academic-policy interface in post-apartheid urban research: Personal reflections. South African Geographical Journal, 89(2):111-120.

Reed VA, Jernstedt GC, Hawley JK, Reber ES \& DuBois CA. 2005. Effects of a small-scale, very short-term service-learning experience on college students. Journal of Adolescence, 28:359-368.

Saltmarsh J. 1996. Education for critical citizenship: John Dewey's contribution to the pedagogy of community service learning. Michigan Journal of Community Service Learning, 3(1):13-21.

Simon C, Mosavel M \& Van Stade D. 2007. Ethical challenges in the design and conduct of locally relevant international health research. Social Science and Medicine, 64(9):1960-1969. 
CHAPTER 12 • HAMMETT \& VICKERS

Stanton T \& Erasmus M. 2013. Inside out, outside in: A comparative analysis of servicelearning's development in the United States and South Africa. Journal of Higher Education Outreach and Engagement, 17(1):61-94.

Thomson AM, Smith-Tolken A, Naidoo A \& Bringle R. 2011 . Service learning and community engagement: A comparison of three national contexts. Voluntas, 22:214-237.

Williams G. 2012. The disciplining effects of impact evaluation practices: Negotiating the pressures of impact within an ESRC-DFID project. Transactions of the Institute of British Geographers, 37(4):489-495. 